\title{
Continuous and Segmented Flow Microfluidics: Applications in High- throughput Chemistry and Biology
}

\author{
Claire E. Stanley, Robert C. R. Wootton, and Andrew J. deMello*
}

\begin{abstract}
This account highlights some of our recent activities focused on developing microfluidic technologies for application in high-throughput and high-information content chemical and biological analysis. Specifically, we discuss the use of continuous and segmented flow microfluidics for artificial membrane formation, the analysis of single cells and organisms, nanomaterial synthesis and DNA amplification via the polymerase chain reaction. In addition, we report on recent developments in small-volume detection technology that allow access to the vast amounts of chemical and biological information afforded by microfluidic systems.
\end{abstract}

Keywords: Droplets · Lab-on-a-chip · Microfluidics · Optical detection · Single cells

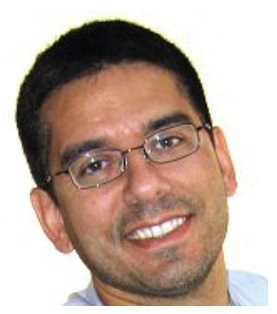

Andrew deMello is Professor of Bio chemical Engineering in the Department of Chemistry and Applied Biosciences at ETH Zürich. He obtained a 1st Class Degree in Chemistry and $\mathrm{PhD}$ in Molecular Photophysics from Imperial College London and subsequently held a Postdoctoral Fellowship in the Department of Chemistry at the University of California, Berkeley. Between 2003 and 2011 he held the Chair of Chemical Nanosciences at Imperial College London. $\mathrm{He}$ is also a co-founder of Molecular Vision Ltd, a

${ }^{\star}$ Correspondence: Prof. Dr. A. deMello Institute for Chemical and Bioengineering Department of Chemistry and Applied Biosciences ETH Zürich

Wolfgang-Pauli-Strasse 10

$\mathrm{CH}-8093$ Zürich

Tel: +41446336610

Fax: +41446331252

E-mail: andrew.demello@chem.ethz.ch company developing low-cost diagnostic devices for use in the doctor's surgery and in the home. The deMello group's activities include the development of microfluidic devices for high-throughput biological and chemical analysis, ultra-sensitive optical detection techniques, nanofluidic reaction systems for chemical synthesis, novel methods for nanoparticle synthesis, the exploitation of semiconducting materials in diagnostic applications, and the development of intelligent microfluidic systems. Prof. deMello has given 250 invited lectures at conferences and universities, and published 180 papers in refereed journals. Science originating from the deMello group has been recognized through the award of the 2002 SAC Silver Medal (Royal Society of Chemistry), the 2009 Clifford Paterson Medal from The Royal Society and the 2009 Corday Morgan Medal (Royal Society of Chemistry).

\section{Introduction}

Microfluidics describes the use of engineered systems to manipulate, process and analyse small volumes of fluids. ${ }^{[1]}$ Over the last two decades the control of fluids on the microscale has been applied to a broad range of problems in the biological, ${ }^{[2]}$ chemical[3] and medical[ ${ }^{[4]}$ sciences.

The development of microfluidic (or lab-on-a-chip) technologies continues apace, ${ }^{[5]}$ primarily due to the need to rapidly analyse small sample volumes and the desirable features that accompany system miniaturisation. ${ }^{[6]}$ For example, microfluidic systems allow $\mathrm{pL}-\mu \mathrm{L}$ fluid volumes to be manipulated in a rapid and controllable fashion, can be produced in large numbers at low cost, leverage efficient thermal and mass transfer, ${ }^{[7]}$ possess small instrumental footprints, afford enhanced analytical performance, enable thousands of discrete samples to be processed per second and allow controlled ${ }^{[8]}$ and fast ${ }^{[9]}$ mixing of reagents. Importantly, microfluidic devices can be manufactured in a wide range of substrate materials, including glasses, polymers, plastics, ceramics, metals and fused silica, ${ }^{[10]}$ with surface modifications facilitating enhanced interfacial properties. ${ }^{[11]}$

Despite the substantial impact that microfluidics has had in chemical and biological analysis, the very features which are beneficial in most situations can be detrimental in others. This is especially relevant for continuous flow microfluidic platforms, which are ideal in applications such as centrifugal fluidics, perfusion platforms and large-scale integration. However, they often become less attractive and more limited due to issues such as Taylor dispersion, solute surface interactions, crosscontamination and the need for substantial volumes of reagents and relatively long channel lengths. ${ }^{[12]}$

Consequently, additional methods of fluid manipulation are required if the full potentials of system miniaturization are to be realised. To this end, the use of segmented flow (or droplet-based) microfluidics has become increasingly popular due to the advantages associated with flow segmentation, which include the elimination of hydrodynamic dispersion and the generation of isolated reaction vessels. Our recent activities in the development of microfluidic techniques for high-throughput chemical and biological analysis have embraced many of the fundamental characteristics of segmented flows. Accordingly, 
this account highlights some of our recent activities that utilise both continuous and segmented flow systems for performing high-throughput and high-information content analysis of chemical and biological environments.

\subsection{Segmented Flows}

As noted, microfluidic technologies that utilise two or more immiscible phases offer significant advantages when compared to continuous flow microfluidic systems. At a primary level, adoption of segmented flows allows the rapid and spontaneous formation of discrete and monodisperse experimental compartments (droplets or slugs). This means that key problems associated with dispersion and dilution of reaction mixtures are at once eliminated. ${ }^{[13]}$ The manipulation of such droplets through winding channels is also advantageous in enabling rapid and efficient mixing. ${ }^{[14]}$ Furthermore, since thousands of droplets may be produced per second, large experimental data sets can be collected in short times allowing sophisticated statistical analyses of complex, multicomponent systems. Of particular note is the use of droplet-based microfluidic systems to perform quantitative analyses of cell populations, at the single cell level, leading to the identification of both rare cells ${ }^{[15]}$ and protein-protein interactions. ${ }^{[16]}$

Segmented flows are typically formed by creating discrete microdroplets that are carried by an immiscible continuous phase along a microchannel. Segmented flows were first realised using capillary formats, where drag forces generated by a co-flowing continuous phase detach drops of a dispersed phase from the end of a small capillary. ${ }^{[17]}$ However, the use of chip-based platforms for droplet generation affords a greater variety of experimental opportunities for subsequent droplet manipulations. The primary methods used to generate droplets in planar chip formats involve the use of shear force ${ }^{[18]}$ and flow focusing ${ }^{[19]}$ geometries. Fig. 1A illustrates the shear force method. Depending on the delicate balance between the oil and aqueous flow rates, two input phases meeting at a junction (often, but not always, shaped as a ' $T$ ') will segment, with the phase having lower affinity for the channel surface forming the discrete phase. More than one aqueous stream can be brought into contact with an oil continuous phase if desired, as illustrated in Fig. 1A. In such a situation the properties of laminar flow are exploited to control the overall composition of the aqueous input. Often, a winding or snakelike channel geometry is incorporated into the channel design shortly after the point at which droplet formation occurs (Fig. 1A). Such features significantly aid mixing of the droplet contents via chaotic ad-

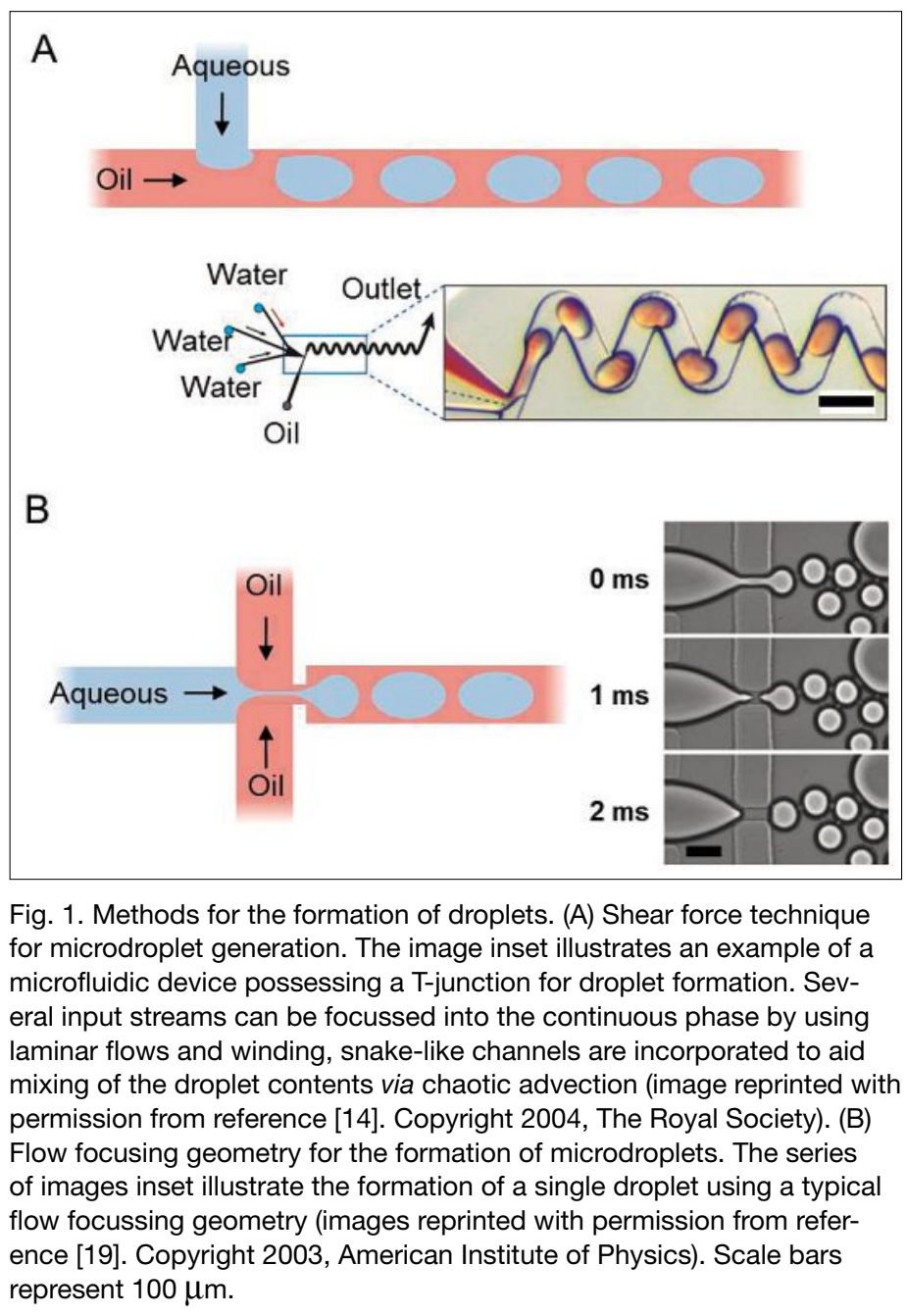

vection, which involves the stretching and refolding of contained fluid strata along a two-dimensional path.[20] Flow focusing geometries can also be used to form segmented flows. The basic principle behind this approach is illustrated by Fig. 1B. Here, three input flows convene and are forced through a narrow orifice, where confinement causes the central stream to destabilise and segment. Droplets of sizes comparable to or smaller than the orifice width can be formed by control of input flow rate ratios. ${ }^{[19]}$

Stabilisation of the liquid-liquid interface within a segmented flow is of high importance when using droplets as vessels in which to perform chemistry and biology. Surfactants may be incorporated in the continuous phase and locate at the oil-aqueous interface, hence stabilising the droplets, preventing droplet coalescence and inhibiting material transfer. ${ }^{[21]}$ However, surfactants do not have to act merely as passive, stabilising entities. For example, Theberge et al. have reported the generation of droplet reactors that possess catalytically active walls. ${ }^{[22]}$ By using surfactant molecules comprised of a fluorous tail and catalytic head group, which assemble at the fluorous-aqueous interface, the authors were able to realise Suzuki-
Miyaura coupling reactions in $\sim 700 \mathrm{~nL}$ aqueous microdroplets.

\subsection{A Droplet Toolbox}

After generating a series of microdroplets in a segmented flow, a variety of 'droplet operations' can be performed to permit complex chemical or biological procedures. Such operations include droplet merging, [23] splitting, ${ }^{[24]}$ synchronisation, ${ }^{[25]}$ sorting, ${ }^{[26]}$ dosing[27] and trapping. ${ }^{[28]}$ The realisation of these operations in integrated formats is vital if microfluidic technologies are to be embraced in future applications. Accordingly, the 'droplet toolbox' is ever expanding to meet the demands of the experimentalist. Some of the recent contributions to the droplet toolbox from our laboratory are now discussed and illustrated in Fig. 2.

Droplet merging can be achieved using either active ${ }^{[29]}$ or passive ${ }^{[23,30]}$ approaches. In 2008, we described a powerful, but passive approach for selective and controllable droplet fusion (Fig. 2A). ${ }^{[23]}$ In brief, the approach exploits differences in hydrodynamic resistance of the continuous phase and surface tension of the discrete phase by using rows of pillars separated by distances smaller than the representative droplet dimension. The benefit of this approach is 


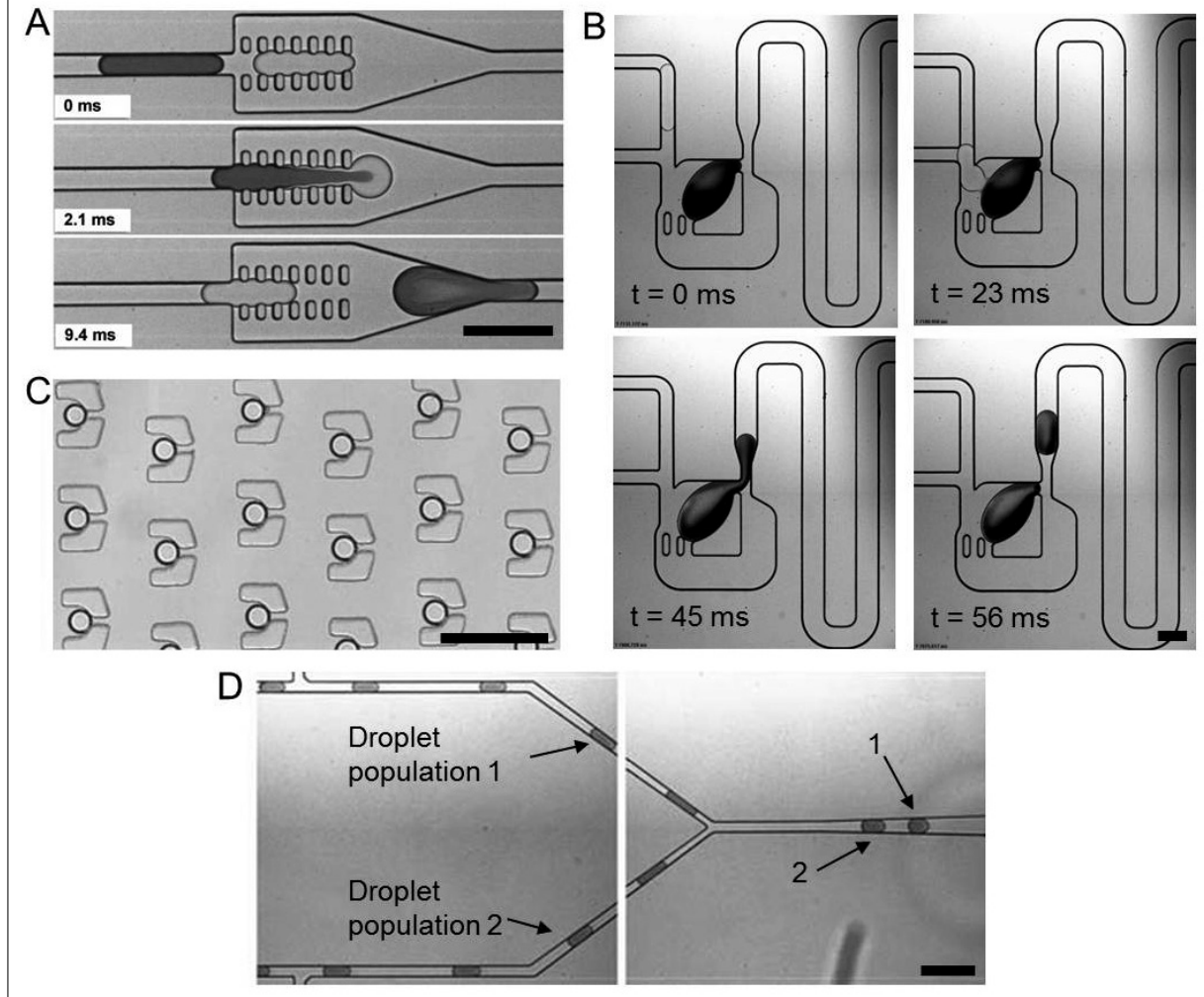

Fig. 2. Recent additions to the droplet 'toolbox'. (A) A passive microfluidic device for droplet merging. ${ }^{[23]}$ Here, two droplets of the same size coalesce, with complete mixing of the two droplets occurring within $\sim 7 \mathrm{~ms}$. (B) A microdroplet dilutor for high-throughput screening. ${ }^{[32]} \mathrm{A}$ buffer droplet approaches a trapped 'mother' droplet $(0 \mathrm{~ms})$, subsequently contacting $(23 \mathrm{~ms})$ and merging with the mother droplet. Activation of the soft valve $(45 \mathrm{~ms})$ finally generates an output droplet (56 ms). The process can then be repeated to yield a sequence of serially diluted microdroplets. (C) An array of trapped microdroplets generated using a microfluidic device, which can subsequently be incubated and released for enzymatic and cell-based assays. ${ }^{[2]}$ (D) A microfluidic device capable of synchronising two droplet populations in a passive manner. ${ }^{[25]}$ All scale bars depicted in this figure represent $200 \mu \mathrm{m}$.

that the merging element can be used to precisely control the timing and nature of droplet merging on a millisecond timescale. Importantly, merging can take place regardless of droplet content and can even (with modification) be accommodated in the presence of high surfactant concentrations. ${ }^{[31]}$ Controllable and selective droplet merging is vital in applications requiring multiple reactive steps and is envisaged to have relevance to reactions performed in sequence.

More recently, we described a passive dilution module that is able to change the concentration of droplets in a rapid and controllable manner (Fig. 2B). ${ }^{[32]}$ Specifically, a nanolitre-sized droplet is trapped in a chamber through use of a soft (pillar-based) valve. Buffer droplets are then delivered into the chamber and via a process of droplet merging, mixing and resplitting, this 'mother' droplet is combined with a series of smaller buffer droplets to generate a sequence of output droplets that define a digital concentration gradient. Importantly, this droplet dilutor enables dilutions spanning four orders of magnitude to be accessed and has enormous implications with respect to conducting high-throughput chemical and biological screens.

Once processed, droplets may often require storage for extended periods of time (for example, to enable a chemical reaction to reach completion or incubate a cellbased assay). There are numerous ways in which droplets may be stored, including the use of traps, ${ }^{[33]}$ reservoirs, ${ }^{[34]}$ and delay channels, ${ }^{[35]}$ For example Huebner et al. described a method for the inclusion of arrays of hundreds of flow-through traps into fluidic beds. Droplets entering a fluidic bed can be efficiently trapped to form static droplet arrays, incubated and subsequently released in a controlled manner (Fig. 2C).[28] Importantly, such arrays have been successful in manipulating single cells for enzymatic and cell-based assays.

\section{Applications of Droplet-Based Microfluidics}

Microfluidic technologies have been exploited to good effect in many fields owing to the advantages previously discussed. The following section highlights a small subset of such applications where we have been and continue to be active. Specifically, we discuss the use of continuous and segmented flow microfluidic technologies for: (i) artificial membrane formation, (ii) the analysis of single cells and organisms, (iii) nanomaterial synthesis and (iv) DNA amplification via the polymerase chain reaction.

\subsection{Artificial Membranes}

Biological membranes are ubiquitous in living organisms and are composed primarily of a bilayer containing amphiphilic lipids and sterols, encompassing proteins, carbohydrates and a cytoskeletal network. ${ }^{[36]}$ They serve to act not only as a means to compartmentalise and regulate the intracellular environment, segregating its contents from the outside milieu, but to perform and choreograph multiple fundamental tasks via sophisticated mechanisms. Many of the intricacies involved in these mechanisms, including the emergence of dynamic coupling between lipids and proteins, ${ }^{[37]}$ have only recently become better understood.

The development of new platforms capable of exploring and elucidating events taking place on and within biological membranes is of undoubted importance. To this end, the formation of artificial lipid bilayers provides a useful way in which to investigate events that affect biological membranes. Furthermore, artificial lipid vesicles (or liposomes) are tuneable in size and can encapsulate predefined media in a controlled manner. They are highly desirable, having numerous applications in the chemical, food and biomedical sciences. ${ }^{[38]}$ Not surprisingly, microfluidic platforms capable of forming artificial bilayer membranes are becoming increasingly evident in the literature, underpinning the need for more controlled, high-throughput methods of artificial membrane production.

The preparation of small unilamellar vesicles (SUVs, 50-200 $\mathrm{nm}$ in diameter, Fig. 3A) using manual methods (such as extrusion) is facile and a popular choice of assay format for biophysical investigations of exogenous species with model lipid membranes. More recently, however, there have been developments in microfluidic technology that allow the generation of SUVs using flow focusing techniques. ${ }^{[39]}$ These techniques are advantageous as the average diameter and size-distribution of an SUV population can be controlled with high precision. The production of monodisperse SUV populations is significant when probing, for example, the effect of membrane curvature upon a given system ${ }^{[40]}$ and for the production of nanoscale vials for confinement. ${ }^{[39]}$

Giant unilamellar vesicles (GUVs, $1-200 \mu \mathrm{m}$ in diameter, Fig. 3A) are also popular model systems for investigating an 


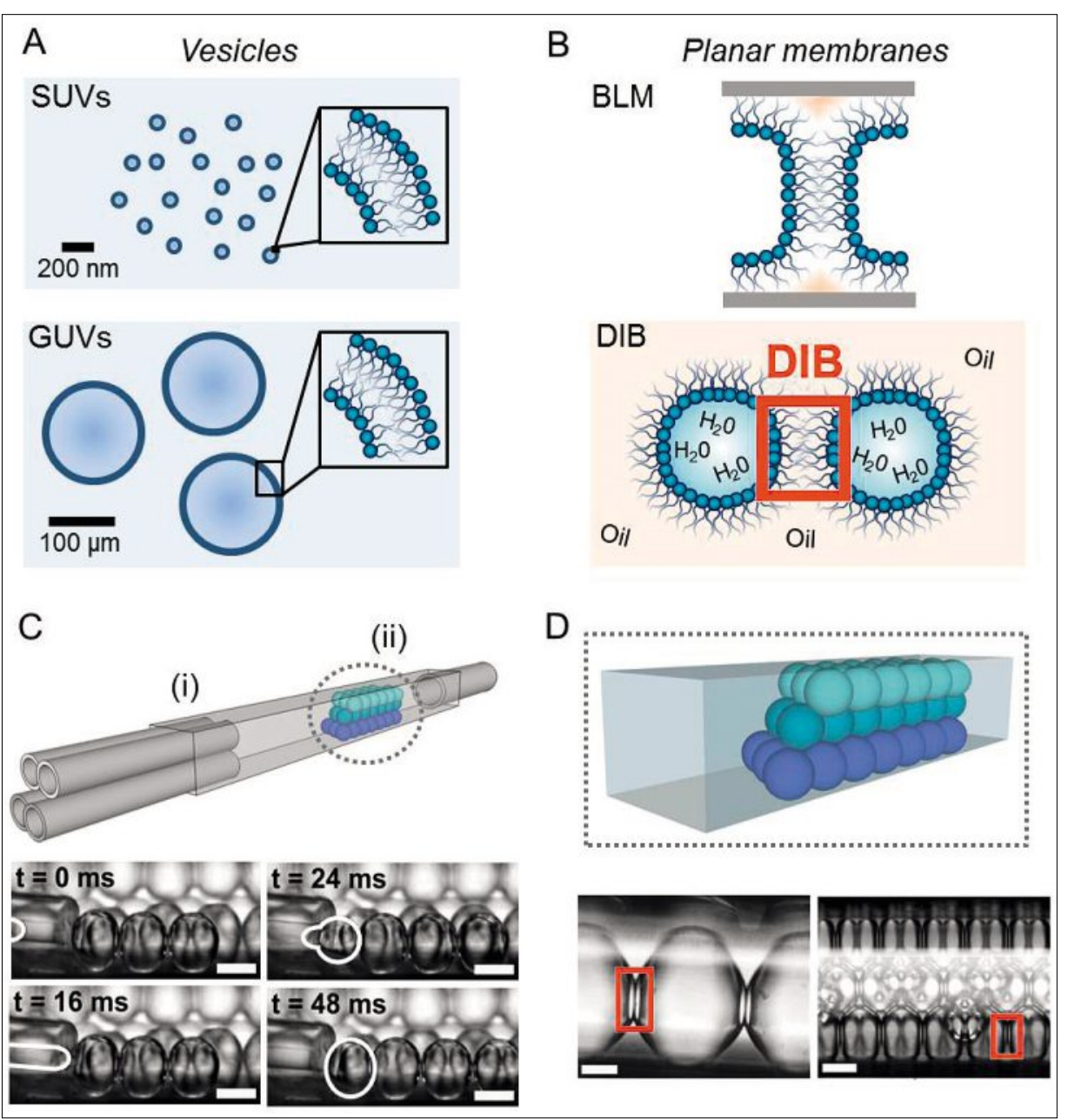

Fig. 3. Lipid membrane platforms. (A) Diagrams illustrating the nature and comparative sizes of small and large unilamellar vesicles (SUVs and GUVs respectively). (B) Illustration detailing two approaches for planar membrane formation: a 'black lipid membrane' (BLM, where the membrane is suspended across an aperture) and a 'droplet interface bilayer' (DIB, where the bilayer forms upon two lipid-containing droplets contacting in an oil environment). Note that the lipid molecules are included for illustrative purposes only and are not drawn to scale. (C) and (D) illustrate a microfluidic approach for DIB formation. ${ }^{\left[{ }^{[3]}\right]}$ (C) A schematic of the experimental set-up, including a series of time frames illustrating formation of water-in-oil droplets (containing lipid vesicles) at point (i) in the microfluidic device depicted here. (D) Examples of the extensive networks of DIBs (1- and 3-dimensions respectively) that can be formed in the microfluidic channel, downstream of the point of droplet entry (point (ii) indicated in (C)). Red boxes denote DIBs. Scale bars in (C) and (D) represent $200 \mu \mathrm{m}$.

expansive range of biological events in real time. Moreover, the larger lumens facilitate their use as minimal cells, vessels for exploring cell motility and as containers of haemoglobin and enzymes in artificial red blood cells. ${ }^{[41]}$ The formation of GUVs, however, is a challenging task: traditional methods for forming GUVs, which include swelling of dried lipid films with aqueous solutions, ${ }^{[42]}$ solvent evaporation ${ }^{[43]}$ and electroformation, ${ }^{[44]}$ rarely produce sufficient numbers of vesicles in the micron range and do not yield monodisperse populations. Attempts have been made to use flow-based and microfluidic strategies for the formation of GUVs, via electroformation methods. ${ }^{[45]}$ These have been successful in generating a plentiful supply of GUVs in solutions of high ionic strength, which is important if physiological conditions are required and often difficult to achieve in non-fluidic systems. However, each of these techniques is compromised by the inability to control both the monodispersity and lamellarity of GUVs. Several methods for forming monodisperse populations of GUVs in high-throughput have been reported. These include the use of pulsed microfluidic jets, ${ }^{[46]}$ continuous droplet interface crossing encapsulation methods, ${ }^{[38]}$ microfluidic T-junctions ${ }^{[47]}$ and dropletbased microfluidics. ${ }^{[48]}$

Artificial lipid bilayer formation using planar formats is an alternative way to generate model biological membranes. Artificial planar bilayers have been utilised for many years, most notably as a tool for probing the functional properties of pore forming proteins, such as alamethicin and gramicidin. ${ }^{[49]}$ 'Black lipid membranes' (or BLMs) were the first artificially produced planar membranes, developed in the early 1960s (Fig. 3B). A variety of approaches for artificial bilayer formation were subsequently developed, including the Montal-Mueller method, ${ }^{[50]}$ pioneered in the early 1970s. Unfortunately, all these techniques are cumbersome in nature, yield membranes that are unstable ${ }^{[51]}$ and are low-throughput.

'Droplet Interface Bilayers' (or DIBs), are a modern twist on the original concept of artificial bilayer formation. ${ }^{[52]} \mathrm{A}$ DIB is a lipid bilayer formed as a result of bringing together two aqueous droplets that are submersed in an oil environment containing lipid molecules. Lipids, being amphiphilic in nature, act as surfactant molecules and assemble at the aqueous-oil interface, reducing the interfacial surface tension and preventing the aqueous droplets from merging instantaneously upon contact. Consequently, a lipid bilayer is formed as a result of two monolayer leaflets coming into contact with one another. Fig. 3B schematically illustrates the nature of a DIB.

In 2010, we demonstrated for the first time an automated, microfluidic approach for the formation of DIBs in high-throughput. ${ }^{[53]}$ At the heart of this approach is the ability to: (i) automate droplet manipulation for DIB formation, (ii) make droplets quickly, (iii) control droplet size and therefore DIB contact area, (iv) form extensive networks of DIBs and (v) form higher order asymmetric DIB systems. Briefly, segmented flows generated using traditional microfluidic techniques for water-in-oil droplet formation are fed directly into the target microchannel (Fig. 3C), in which DIBs are able to form downstream (Fig. $3 \mathrm{D})$. By varying the volumetric flow rate, droplet volume (and hence the DIB contact area) can be controlled.

The use of a microfluidic approach further widens experimental parameter space, enabling the complexity of DIB networks in terms of dimensionality (i.e. whether the droplets stack in 1-, 2- or 3-dimensions) and membrane complexity (i.e. the introduction of bespoke membrane composition, including asymmetry) to be varied. The former point is dependent upon the relationship between the droplet radius and channel dimensions (height, width and length), which can be easily tuned, and can be used to fill pre-defined microfluidic moulds. The latter point is achieved by introducing more than one droplet type (containing different lipid vesicle compositions) in controlled arrangements. We envisage this technology will underpin a diverse range of applications including tissue engineering scaffolds and photonic materials, as well as providing a platform upon which to explore the importance of membrane-related phenomena, such as the role of asymmetry in cellular function. 


\subsection{Single Cell and Organism Analysis}

Mutations at the single cell level are pivotal in disease processes. Accordingly, the development of new tools and techniques able to isolate and interrogate single cells (and sub-cellular organelles) from heterogeneous populations is crucial in furthering our understanding of basic biological processes. The analysis of single cells is important since it enables an understanding of cellular heterogeneity that is impossible using ensemble averaged techniques, and provides a direct route to the detection of rare biological events. For example, the way in which different cell components align both spatially and temporally is of fundamental concern in our understanding, and hence exploitation, of signalling networks. ${ }^{[54]}$

There exist a variety of microfluidic tools for manipulating and assaying single cells. These include platforms for controlled cell lysis and capture of cellular components, ${ }^{[55]}$ optically trapped lipidcoated oil droplets for probing the plasma membrane content of single cells (via connective membrane tethers), ${ }^{[54]}$ platforms for assessing the mechanical properties of single cells (to screen for diseases such as malaria), ${ }^{[56]}$ single cell discrimination in flowing streams, ${ }^{[57]}$ platforms that utilise microarray technologies ${ }^{[58]}$ and dropletbased microfluidics ${ }^{[59]}$ for quantitative analyses via stochastic confinement. The method of choice is ultimately determined by the desired application, though the continued development of droplet micro fluidic technology for studying single cells is a major focus in our laboratories, owing to the fact that quantitative analyses can be performed on cell populations in both a rapid and precise manner.

Droplet microfluidics provides a direct and efficient means of compartmentalising single cells. By controlling the flow rates of input streams and the microfluidic channel geometries, single cells from a larger population may be trapped within a single aqueous microdroplet that is embedded in an oil continuous phase, as illustrated in Fig. 4A. When coupled with downstream detection, a true representation of an entire cell population can be formed leading to the identification of rare cell states. ${ }^{[58]}$ For example, droplet-based microfluidics has been used to identify rare progenitor cells from human periosteal tissue. ${ }^{[15]}$ In this study, specific cell-surface properties were selected and used to identify both typical and atypical cell types present within a heterogeneous cell culture.

A further advantage associated with confinement is that the products of any processes involving the single cell are entrapped and confined within the associated micro-vessel. Molecular dispersion is

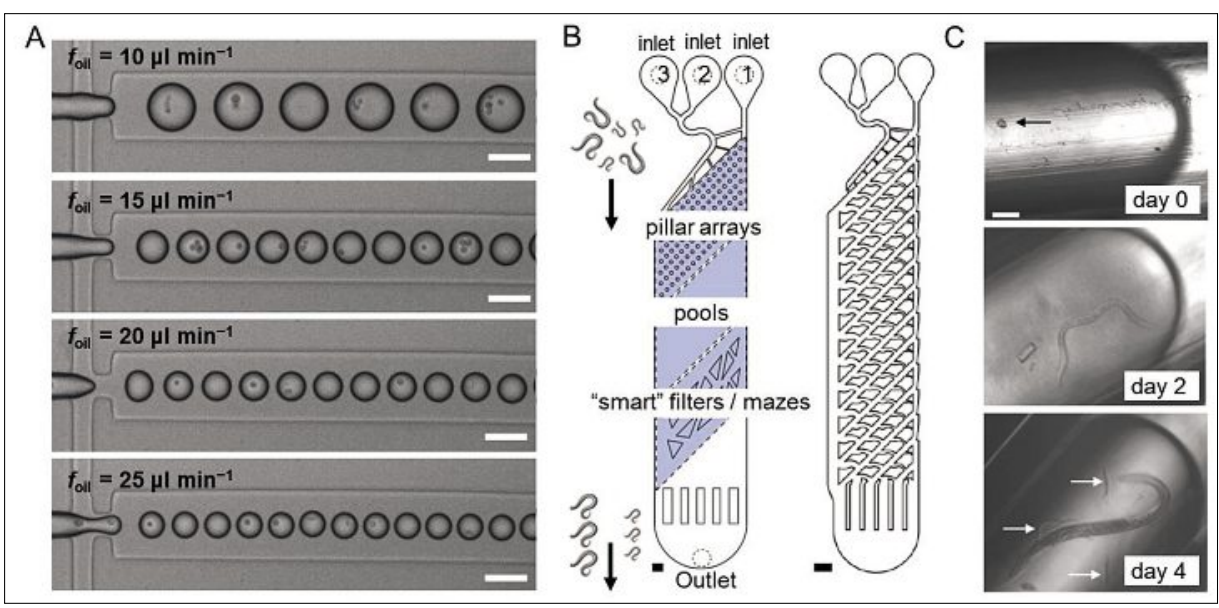

Fig. 4. Continuous and segmented flow microfluidics for investigations conducted on single cells and organisms. (A) Tuning of cell occupancy within microdroplets, via manipulation of oil and aqueous flow rates, for performing measurements on single cells. ${ }^{[60]}$ Note that the flow rate of the cell-containing phase remained constant in each image $\left(5 \mu \mathrm{L} \mathrm{min}{ }^{-1}\right)$. Scale bars represent $100 \mu \mathrm{m}$. Image reprinted with permission from reference [60]. Copyright 2010, IOP Publishing. (B) Graphical representation of a conceptual (left) and optimised (right) microfluidic sorter of Caenorhabditis elegans on the basis of age and size. ${ }^{[71]}$ The passive microfluidic sorter possesses three fluid inlets, a 'body' containing the separation strategy (pillar arrays, pools, 'smart' filters and mazes were tested), six sorting channels and a single outlet. The best separation of worms was found to be based on a 'smart' maze strategy (right). Scale bars represent $1 \mathrm{~mm}$. (C) Growth of Caenorhabditis elegans within aqueous microdroplets for high-throughput screening. ${ }^{\text {[2] }}$ Eggs (black arrow) were encapsulated and their growth tracked over a period of days. Larvae from a second generation of encapsulated worms were observed after day 4 (white arrows). Scale bar represents $100 \mu \mathrm{m}$. Images reprinted with permission from reference [72]. Copyright 2008, Elsevier.

prevented and hence the amplitude of any signal is vastly enhanced. An elegant example of such an approach has been demonstrated by Huebner et al., where picolitre-sized microdroplets have been used to detect the presence of alkaline phosphatase expressed by $E$. coli cells. ${ }^{[61]}$ Here a fluorogenic substrate, 3-O-methylfluorescein phosphate (OMFP), is encapsulated with small numbers of $E$. coli cells inside picolitre-volume droplets. Upon expression of the enzyme, OMFP is dephosphorylated to form the fluorescent product, 3-O-methylfluorescein (OMF). Detection of $\mathrm{OMF}$ is then used to probe enzyme kinetics and activity. Confinement of reagents in this way enables the enzymatic activity of single cells to be probed with high precision and in high-throughput and represents an ideal format for directed evolution experiments, where genotype and phenotype may be linked.[62]

The process of single cell encapsulation within microfluidic droplets does not only afford the aforementioned benefits associated with confinement. It has also been combined with bio-electrospraying (BES) to control cell numbers within droplets and encapsulations. ${ }^{[60]}$ In work by Hong et al., the feasibility of coupling BES with droplet-based microfluidics was demonstrated with the expectation that the combination will enable cell occupancy in droplets to be self-controlled. This is an important development since BES has application in a number of fields, including tissue engineer- ing, regenerative biology and medicine. As has been shown, droplet microfluidics as a tool in single cell analysis not only affords ease of use, with respect to handling small volumes of liquid, but it opens new avenues. For example, the production and detection of droplets that possess picolitre volumes, as well as the ability to beat Poissonian statistics (i.e. to exclude unoccupied droplets), ${ }^{[63]}$ enables high sensitivity and high detection efficiency analysis of single cells.

The ability to conduct separations of complex chemical and biochemical mixtures is critical in many aspects of analysis. The miniaturisation of many standard separation technologies has been shown to yield high separation efficiencies and reduced separation times. ${ }^{[64]}$ Indeed, the development of microfluidic devices capable of performing chemical separations has been an important focus of activities in our group. Much of our early work was focussed on the development of on-chip electrophoretic systems. ${ }^{[65]}$ More recently however, we have demonstrated new ways in which droplet-microfluidics may be used to perform high efficiency separations. ${ }^{[66]}$ For example, Vijayakumar et $a l$. described a novel method for liquidliquid cell extraction, using an aqueous, two-phase microdroplet system. ${ }^{[67]} \mathrm{By}$ exploiting channel geometry to control droplet form, a snake-like microfluidic channel could be used to extract Human T lymphoma cells. Specifically, the width of 
the winding microchannel is designed to narrow as the segmented flow progresses through the device, consequently squeezing and elongating the droplets and resulting in mixing of the two liquid phases (polyethylene glycol and dextran). Upon relaxation of the aqueous droplets (due to widening of the microchannel), the two liquids separate once again and the cells are extracted from the dextran and into the polyethylene glycol phase.

In addition to the study of single cells, microfluidic systems have also been applied to the investigation of single, multicellular organisms, such as Caenorhabditis elegans (invertebrate worms) and Danio rerio (vertebrate zebrafish). ${ }^{[68]}$ The study of these organisms is important as they provide simple, whole organism models that can be used to aid understanding of disease, ageing and development. ${ }^{69]}$ Caenorhabditis elegans has a generation time of only 3-5 days, a short lifespan ( 23 weeks), a small size (larvae, $\sim 250 \mu \mathrm{m}$; adults, $\sim 1 \mathrm{~mm})^{[68]}$ and produces isogenic populations (due to asexual reproduction). Although the generation time, lifespan and size are greater for Danio rerio (3-4 months, 3-4 years and 3-5 cm respectively), ${ }^{[68]}$ the organism is more complex than Caenorhabditis elegans and subsequently enables a wider range of biology to be investigated. For these reasons, novel ways in which to manipulate such organisms are needed to gain detailed and specific information in a controlled and rapid manner. Microfluidic systems fulfil these requirements and are therefore becoming a powerful experimental platform for studies involving organisms. ${ }^{[70]}$ We have recently developed a high-throughput, self-sorting device, which can discriminate a population of Caenorhabditis elegans on the basis of age and size in a passive manner (Fig. 4B). ${ }^{71]}$ Due to their short generation time, Caenorhabditis elegans form mixed populations that contain young larvae, as well as adults. Studies concerning ageing require age-synchronised organism populations, hence these mixed populations need to be separated continuously. The sorter functions through the ability (or inability) of an individual to interact with channel walls and affords a throughput of up to $1.73 \times 10^{6}$ worms per day, which is considerably higher than any methods currently reported.

Droplet-based microfluidic technologies have also been employed to encapsulate and study multicellular organisms. The advantages associated with single organism encapsulation using droplet-based microfluidics are analogous to those described previously for single cell encapsulation (such as signal enhancement due to confinement, the ability to work at the single-organism level, as well as the ability to assay large numbers of organisms).[58] For example, Clausell-Tormos et al. have demonstrated Caenorhabditis elegans egg encapsulation and growth within microdroplets (Fig. 4C), ${ }^{[72]}$ whilst Shi et al. have generated and immobilised arrays of microdroplets containing single Caenorhabditis elegans nematodes for assaying their behaviour upon exposure to neurotoxins. ${ }^{[73]}$ Importantly, each of these developments paves the way for high-throughput assaying of multicellular organisms with single animal resolution.

\subsection{Controlled Synthesis of Nanoparticles}

The controlled synthesis of nanometresized colloids is an essential challenge in nanoscale science. Of particular relevance is the use of nanoparticles as probes in biology and medicine. Semiconductor quantum dots have the ability to act as in vivo bioimaging agents, primarily due to their photoluminescent properties and potential to target tumours with high specificity. ${ }^{[74]}$ For example, CdTe/CdSe nanoparticles have been found to be uptaken specifically by the sentinel lymph nodes and can be used to aid their removal during cancer surgery. ${ }^{[75]}$ As photoluminescent probes, quantum dots have extremely high fluorescence quantum efficiencies and low photodegradation rate coefficients making them preferable to small molecule fluorophores.

Since the physical dimensions of the crystallites determine both their electronic and optical properties, there is considerable interest in synthetic routes that yield nanoparticles of well-defined size and shape. Although high quality particles with narrow size distributions can be prepared on the gram scale via standard synthetic methods, these are typically complex, costly or require post-hoc treatment to select nanoparticles of the desired size. ${ }^{[76]}$ Accordingly, the need for better size-selectivity, stricter control over particle properties, and batch-to-batch reproducibility demands alternative and improved production methods. In recent years, microfluidic reactors have emerged as a powerful tool in nanoparticle synthesis since they provide higher levels of control over system variables such as reagent concentration, reaction time, temperature and pressure when compared to conventional macroscale formats (Fig. 5A). ${ }^{[77]}$ This means that particle nucleation and growth can be controlled in both time and space, with each nucleus growing under identical experimental conditions. ${ }^{[78]}$ Moreover, we have shown that through integration with appropriate detection systems product analysis can be performed on-line ${ }^{[79]}$ and controlled intelligently via feedback mechanisms (Fig. $5 \mathrm{~B}),{ }^{[80]}$ significantly reducing the amounts of expensive or toxic materials required. ${ }^{[81]}$
Both gas-liquid and liquid-liquid segmented flow systems have been used to further enhance the quality and complexity of nanoparticle populations. ${ }^{[82]}$ Crucially, compartmentalisation using droplets or slugs prevents the loss of reagents and product to channel walls and removes problems associated with product accumulation and residence time distributions. For example, Shestopalov et al. demonstrated that segmented flow, two-step microfluidic reactors can be used for the controlled synthesis of $\mathrm{CdS}$ and CdSe quantum dots at room temperature. ${ }^{[83]}$ Both nanoparticle size and composition were controlled by including an additional inlet channel downstream of the droplet generator. Here, a secondary droplet or continuous stream of material can be introduced and merged with the initial droplet population. Very recently, we have also demonstrated the use of a passive, capillary-based microfluidic reactor for the controlled synthesis of dextran-coated superparamagnetic iron-oxide nanoparticles (SPIONs) in droplets. ${ }^{84]}$ In this study, Kumar et al. demonstrate that low polydispersity SPIONs, possessing high saturation magnetisations and good MRI contrast enhancement properties, can be synthesised in a direct manner. Importantly, the use of segmented flows enables fast and controlled mixing (on the millisecond time scale) which significantly contributes to improved product yields and monodispersity. ${ }^{[85]}$

Finally, synthesis temperatures are often increased in order to increase the quality of the quantum dot population by annealing surface defects. However, such a strategy requires solvents that are able to dissolve the starting reagents at ambient temperatures whilst remaining liquid at the high operating temperatures. ${ }^{[76]}$ These constraints mean that solvent choice, and therefore nanoparticle synthesis, is somewhat limited. To this end, Marre et al. have developed a method that utilises high pressures for the controlled synthesis of nanoparticle in microfluidic devices. ${ }^{[86]}$ Their approach enables a wider choice of solvents and also allows for a greater control over supersaturation, which can often limit dispersity loss due to Ostwald Ripening.

\subsection{DNA Amplification via the Polymerase Chain Reaction}

The polymerase chain reaction (PCR) is a critical tool in modern biological science. ${ }^{[87]}$ PCR acts to amplify specific nucleic acid sequences in vitro and has wide application in the forensic sciences, clinical diagnostics, evolutionary biology, cloning and sequencing. The fundamental requirement for efficient amplification is rapid heat transfer. Consequently, it is desirable to have a system with a low heat capacity that can transfer heat quickly in and out. 

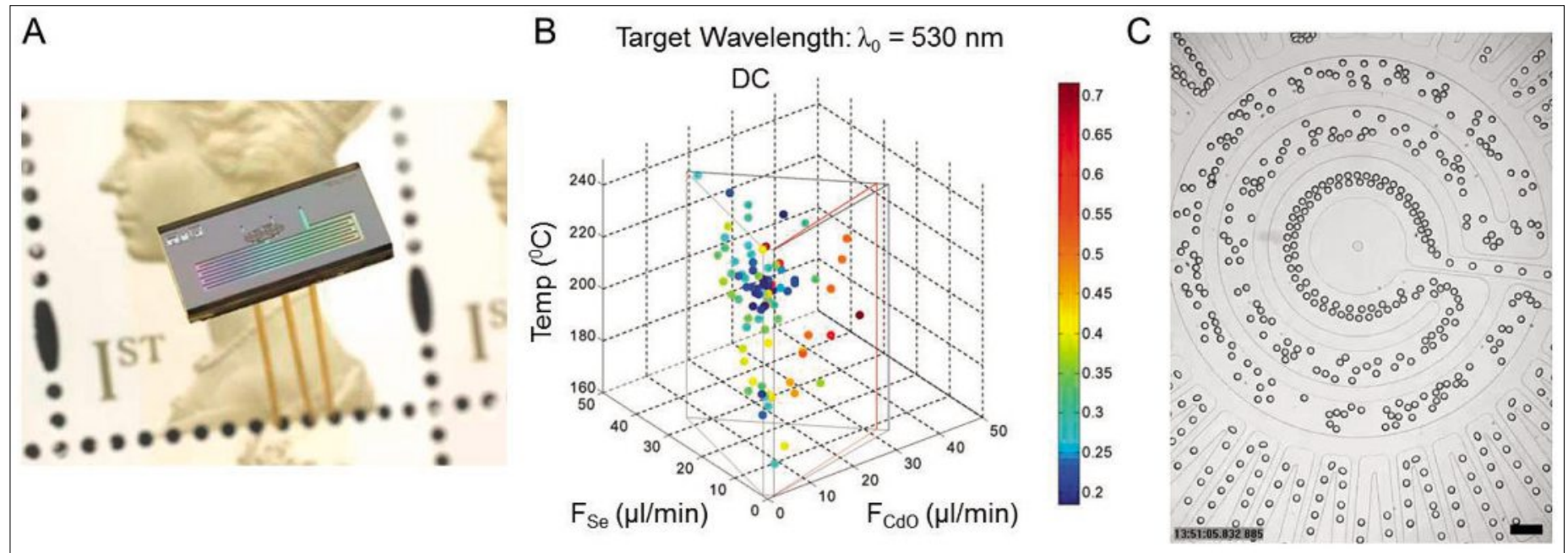

Fig. 5. Continuous and segmented flow microfluidics for nanoparticle synthesis and DNA amplification via the polymerase chain reaction (PCR). (A) An example of a microfluidic reactor used for nanoparticle synthesis, which can provide higher levels of control over system variables (reagent concentration, reaction time, temperature) when compared to conventional macroscale formats. (B) A scatter plot showing the results of an intelligent system for optimised nanoparticle synthesis. ${ }^{[80]}$ The influence of $\mathrm{CdO}$ flow rate $\left(\mathrm{F}_{\mathrm{CdO}}\right)$, Se flow rate $\left(\mathrm{F}_{\mathrm{Se}}\right)$ and temperature on the value of the dissatisfaction coefficient (DC) is assessed for a target wavelength of $530 \mathrm{~nm}$. The DC ranges from 0 to 1 , with a value of 0 meaning complete satisfaction has been gained. The flow rate and temperature constraints are defined by the grey framework and the red lines indicate the flow conditions yielding a $1: 1$ ratio of $\mathrm{Cd}$ to $\mathrm{Se}$ in the reaction mixture. (C) A microfluidic PCR device, which achieves 34 PCR cycles in continuous flow droplet operation and operates at the single copy level. ${ }^{[91]}$ Aqueous droplets, containing the PCR reagents and carried in an oil continuous phase, pass through the inner circles in the hot zone to ensure initial denaturation of the template and travel away from the centre and onto the cooler periphery in microchannels, where primer annealing and template extension occur. The droplets then flow back to the centre, where the DNA is denatured and a new cycle commences. Scale bar represents $500 \mu \mathrm{m}$.

Almost all conventional thermal cyclers possess large thermal masses. This results in relatively high power requirements and slow heating and cooling rates. Conversely, the small thermal masses associated with microfluidic systems make then ideally suited to performing high-efficiency PCR on short timescales. Not surprisingly, both batch and continuous flow microfluidic devices for PCR have been intensively investigated over the past twenty years. For example, in 1998, Kopp et al. exploited microfabrication techniques to develop the first continuous flow PCR system. ${ }^{[88]}$ Using simple glass devices, 20-cycle PCR amplifications of a 176 base pair fragment from a DNA gyrase gene were performed in times as short as 90 seconds. In addition, integration of the batch PCR and capillary electrophoresis (for product sizing) on a single microdevice was achieved by Woolley et al. for the first time in 1996, demonstrating the feasibility of performing high-speed DNA analyses in integrated fluidic systems. ${ }^{[89]}$

More recently, the concept of 'digital', or 'emulsion-based', PCR (via stochastic confinement) was introduced to avoid amplification biases present in bulk populations, and therefore enable the quantification of rare populations. ${ }^{[90]}$ Droplet-based PCR is a natural outgrowth from this idea. Here the use of segmented flows provides a simple and direct way of ensuring amplification from single template molecules, by partitioning samples into vast collections of monoclonal (sub-nanoliter volume) droplets, where each droplet ei- ther contains zero or one DNA template. A key additional feature of this approach is the prevention of interactions between target DNA and polymerase enzyme with the microchannel surfaces, which leads to significant improvements in amplification efficiency. To this end, Schaerli et al. described a microfluidic device capable of performing PCR in continuous flow where reagents are encapsulated within $\mathrm{pL}$-volume droplets surrounded by a continuous oil phase. ${ }^{[91]}$ Using such a device the authors demonstrated single copy PCR in approximately 15 minutes and amplification factors of up to $5 \times 10^{6}$ (Fig. 5C).

The amalgamation of droplet microfluidics with the PCR technique has led to a plethora of applications, such as directed evolution, disease diagnosis and gene expression. An excellent review by Zhang $e t$ al. provides a thorough synopsis of current applications of single-molecule DNA amplification and analysis using microfluidics and should be consulted for further information. ${ }^{[92]}$

\section{Detection in Small Volume Environments}

Despite the numerous performance advantages engendered by microfluidic systems the manipulation of chemical and biological samples with volumes ranging from a few picolitres to hundreds of microlitres represents a substantial challenge for analyte detection and identification, and ultimately defines the primary limitations of many microfluidic systems. Indeed, whilst microfluidic systems are capable of producing vast amounts of chemical and biological information, the majority of this will be lost or wasted if the detection method employed is lacking. A detailed discussion of detection methods used in small-volume environments can be found elsewhere, ${ }^{[93]}$ however, efficient detection will be defined by a close interrelationship of properties such as detection limits, sensitivity, response times and information content. Studies in our laboratory have focused on many aspects of small-volume detection, some of which are described below.

\subsection{Laser-induced Fluorescence}

The exquisite sensitivity and selectivity associated with fluorescence spectroscopy is well suited to probing small volumes and low analyte concentrations in a non-invasive manner. Moreover a wide variety of established biochemical methods incorporate fluorescent chemistries, making their transferral to planar chip formats trivial, and huge improvements in light source, optical and detector technologies have expanded the functionality of the basic measurement process. Accordingly, a variety of fluorescence-based methods have been used in conjunction with microfluidic systems.

\subsubsection{Single-molecule Detection}

The most popular methods for singlemolecule detection within microchannel systems make use of confocal fluorescence 


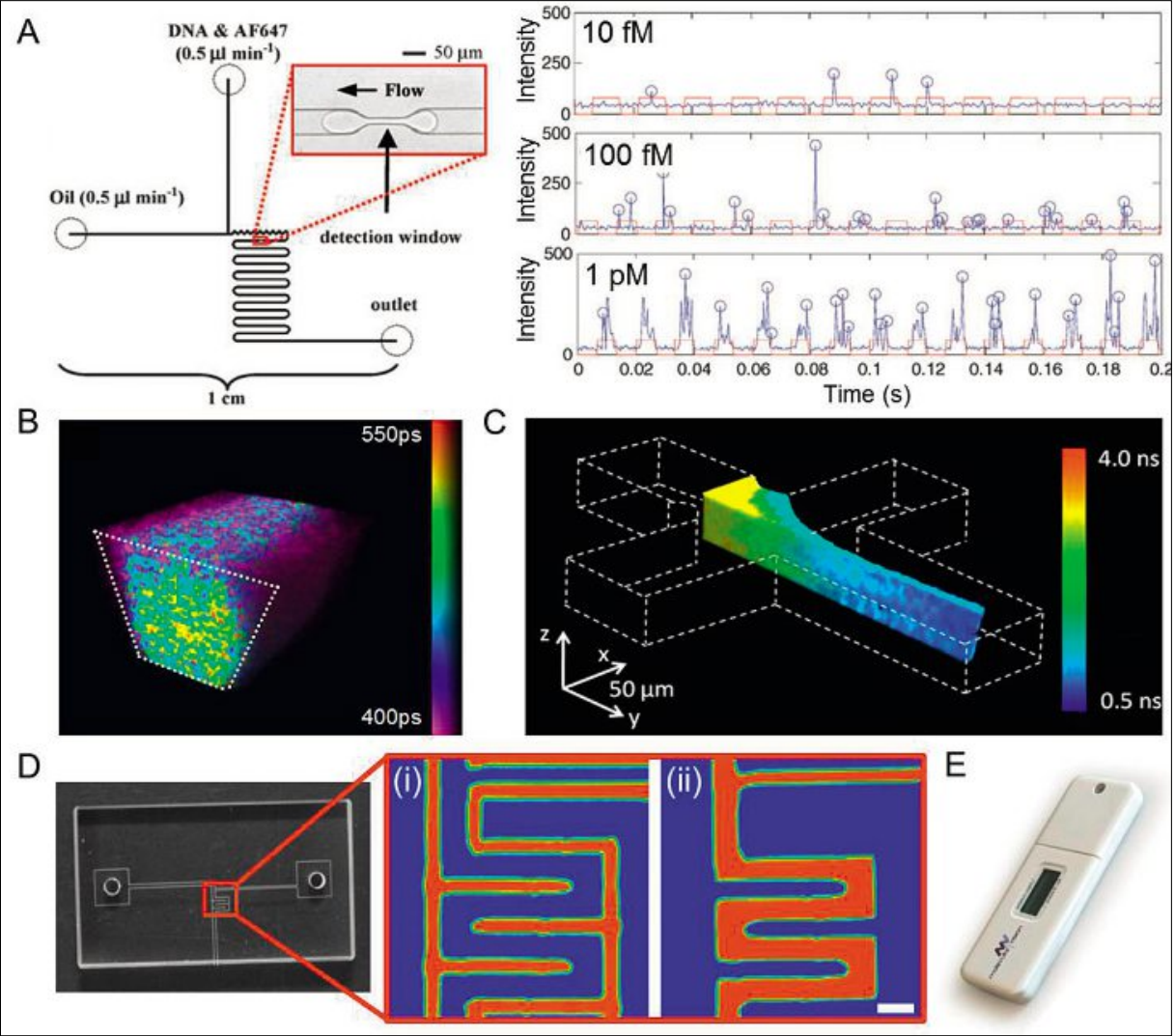

Fig. 6. Small volume detection methods used in microfluidic technology. (A) Confocal fluorescence spectroscopy for single molecule detection. This device achieves improved detection efficiencies by squeezing aqueous droplets carried in oil through channel constrictions (the 'detection window'), where a laser beam illuminates the cross-sectional area of the microchannel in a uniform manner ${ }^{[101]}$ Fluorescence burst scans of a dilution series of DNA-YOYO-1 are shown. The number of DNA molecules per unit time increases as a function of DNA concentration - single DNA molecule occupancy was achieved at $10 \mathrm{fM}$. (B) Three-dimensional (3D) temperature mapping of fluidic temperatures using fluorescence lifetime imaging (FLIM). ${ }^{[105]}$ Variations in the fluorescence lifetime of a methanolic rhodamine $B$ solution are illustrated upon maintaining the temperature of the upper surface in a microchannel at $73^{\circ} \mathrm{C}$ (image reprinted with permission from reference [105]. Copyright 2006, American Chemical Society). (C) 3D image of fluorescence lifetime variations within a microfluidic mixer. ${ }^{[107]} \mathrm{A}$ stream of fluorescein is focussed using two fluidic streams containing $\mathrm{Nal}$ (a quencher of fluorescein) and their mixing dynamics probed. (D) Fourier transform infrared (FTIR) spectroscopy for imaging continuous flows in microfluidic devices. ${ }^{[12,115]}$ An image of a microfluidic device is displayed; a paraffin pattern is printed onto a $\mathrm{CaF}_{2}$ window (white lines) to define the microchannels, which is then sandwiched with a second window to seal the device. Images of the paraffin device based on (i) the absorbance of paraffin at $1462 \mathrm{~cm}^{-1}$ and (ii) the absorbance of water at $1640 \mathrm{~cm}^{-1}$ upon filling the microfluidic channel with water are displayed. Scale bar represents $500 \mu \mathrm{m}$. (E) An example of a microfluidic device used for point-ofcare diagnostics, developed by Molecular Vision.

spectroscopy. ${ }^{[94]}$ Confocal fluorescence detection involves the use of a femtolitre probe volume, defined using a focused laser beam, and a confocal pin hole. ${ }^{[95]}$ When a fluorophore passes through the probe volume, it will emit a burst of fluorescence photons through repetitive photon absorption-emission during its transit, thus reporting its presence. Molecules suitable for single-molecule detection should possess a high fluorescence quantum efficiency and a low photodegradation rate coefficient.

Confocal systems have been used for single molecule detection in a variety of studies, including the measurement of binding kinetics, ${ }^{[96]}$ the determination of nanoparticle flow and size ${ }^{[97]}$ and the realisation of single-molecule kinetic and dynamic studies in isolated chambers over extended time periods. ${ }^{[98]}$ Furthermore, time-resolved single-molecule fluorescence confocal spectroscopy has been shown to be efficient in discriminating single Escherichia coli cells expressing different fluorescent proteins. [99]

Although the above methods are successful in detecting single molecules they are characterised by poor molecular detection efficiencies since the majority of molecules never enter the probe volume. In continuous flows, this situation can be improved by hydrodynamically focussing the analyte stream through the confocal probe volume. ${ }^{[100]}$ Droplets have also been used as a means to further enhance detection efficiencies. Aqueous droplets carried in oil may be squeezed through channel constrictions, where a laser beam illuminates the cross-sectional area of the microchannel in a uniform manner, as illustrated in Fig. 6A. ${ }^{[101]}$ Hence, the large majority of molecules contained within the droplet will pass through the confocal probe volume. Segmented flow microfluidics also offers an additional dimension, in that droplet generation can occur at $\mathrm{kHz}$ frequencies, thus enabling single molecule analyses to be conducted in a highthroughput manner. ${ }^{[102]}$ This contrasts to other platforms such as that proposed by Sakakihara et al., where femtolitre droplet arrays are used for a single-molecule enzymatic assays. ${ }^{1103]}$ Such static arrays, which can contain $10^{6}$ droplets, allow each droplet to be individually addressed, however, high-throughput assays can only be performed if an automated micropipetting system is implemented.

\subsubsection{Fluorescence Lifetime Imaging (FLIM)}

Fluorescence lifetime imaging (FLIM) is a powerful detection modality that greatly increases the information attainable from basic time-integrated measurements. FLIM is a ratiometric technique that does not require calibration prior to each experiment (unlike time-integrated fluorescence) and can report on environmental parameters such as temperature, $\mathrm{pH}$, polarity and viscosity with high spatial and temporal precision. When used in conjunction with microfluidic systems, FLIM can retrieve chemical information that is otherwise inaccessible. For example, Benninger et al. described the use of FLIM in capturing kinetic information regarding non-equilibrium states of DNA-dye intercalation, ${ }^{[104]}$ whilst both Benninger et al. and Robinson et al. have used FLIM to measure fluidic temperatures with micron spatial resolution (Fig. 6B). ${ }^{[105]}$

FLIM has also been used to investigate mixing dynamics in flowing droplets (of pL-volume) with a temporal resolution of $5 \mu \mathrm{s},{ }^{[9]}$ and more recently $1 \mu \mathrm{s} .{ }^{[106]}$ In addition to providing complex information concerning biological or chemical events, FLIM can be utilised as a tool to monitor fluid flow. For example, Robinson et al. have used FLIM to create three-dimensional maps of mixing profiles (that compare well with computational fluid dynamics simulations) within hydrodynamic mixers (Fig. 6C). ${ }^{[107]}$ Moreover, Benninger et $a l$. have used FLIM to quantitatively map (in three dimensions) variations in solvent viscosity. ${ }^{[108]}$

\subsection{Label-Free Detection}

Although fluorescence-based methods offer exquisite sensitivity and selectivity they require the presence of fluoro- 
phores within the sample. Since only a small proportion of molecules fluoresce the introduction of extrinsic fluorophores via chemical labelling is often required. This not only adds to the complexity of sample preparation but yields analogues which may not be representative of native species. As a result, there has been much interest in integrating label-free detection techniques with microfluidic systems. Examples include refractive index variation, ${ }^{[109]}$ Raman spectroscopy, ${ }^{[110]}$ surfaceenhanced Raman spectroscopy (SERS), [111] Fourier transform infrared (FTIR) spectroscopy (Fig. 6D), ${ }^{[12]}$ attenuated total reflection (ATR)-FTIR spectroscopy[113] and mass spectrometry. ${ }^{[114]}$ Although these techniques are usually less sensitive than fluorescence-based methods, their chemical specificity and quantitative nature render them a valuable and potentially a more important addition to the detection tool box. Specific recent highlights from our laboratory include the establishment of FTIR ${ }^{[115]}$ and ultrafast surface enhanced resonance Raman scattering (SERRS) detection methods with sub-millisecond time resolution $^{[16]}$ for probing droplet-based microfluidics.

\subsection{Detector Integration}

There exists significant interest in developing highly integrated and small-footprint point-of-care diagnostics devices. As discussed, microfluidic systems, on paper at least, represent an ideal format for such applications. They can efficiently manipulate small amounts of sample, can be mass-fabricated at low unit cost, can be operated by inexpert personnel and are able to operate in resource-poor environments. In recent years, a number of prototype microfluidic diagnostic devices have been reported and refined, such as that illustrated in Fig. 6E. These advances have been described by Yager et al., ${ }^{[117]}$ who conclude that a significant challenge associated with the successful deployment of microfluidic diagnostics relates to reducing unit costs to a level competitive with current lateral flow assays. A key factor in achieving this goal is the ability to perform sensitive and quantitative analyte detection at low cost and in an integrated format. To this end, we have a long-standing interest in integrating optical detection systems within planar chip formats. An in depth introduction to organic semiconductor-based optical detection in point-of-care devices has been presented by Hofmann et al. ${ }^{[118]}$ Accordingly, only a brief overview of our activities is given herein. As explained previously, fluorescence spectroscopy is the most popular detection technique used in biochemical analysis. Hence, the ability to integrate (at low cost) excitation sources, photon detectors and optical filters within monolithic substrates is essential in realising point-of-care tests based on accepted laboratory methods.

Thin-film organic light emitting diodes (OLEDs) and more especially polymer LEDs (pLEDs) are ideal candidates for integrated light sources. A generic pLED comprises one or more organic layers sandwiched between two electrodes (one of which is transparent). On application of a small voltage across the electrodes, the polymer layer will emit light via radiative recombination of injected electrons and holes, thus acting as a light source. Interestingly, the emission characteristics are determined by the chemical nature of the polymer, and may thus be tuned using standard synthetic methods. Additionally, most polymeric emitters are soluble, allowing for low-cost deposition from solution, e.g. by inkjet printing. To this end, we have integrated thin-film pLEDs as onchip excitation sources for the detection of microalbuminuria ${ }^{[119]}$ and chip-based capillary electrophoresis..$^{[120]}$ In addition, the basic pLED device architecture can be used in reverse as a photon detector.[121] Indeed, Hofmann et al. have shown the use of integrated thin-film copper phthalocyanine-fullerene photodetectors for performing chemiluminescence assays, where photons are generated as a result of chemical excitation and hence do not require an optical excitation source. ${ }^{[122]}$

Optical filters are basic tools in most spectroscopic measurements and used to prevent the excitation radiation flooding the detector. They are especially important for integrated detection in microfluidic devices, since fluorescence emission is not collected orthogonal to the excitation source to ensure low fabrication costs. Hofmann et al. have shown that lysochrome dyes can be incorporated into the substrate of elastomeric devices to form integrated short-pass, band-pass and long-pass filters. ${ }^{[123]}$ This enables high signal-to-noise ratios whilst also minimising device complexity. Importantly, filter performance is high, comparing well with commercially available (and expensive) macroscale analogues. One potential disadvantage with dye-doped filters is substrate autofluorescence. Indeed, the presence of even very low levels of autofluorescence from the dye molecules located in the filter is unacceptable. A low cost approach for the fabrication of non-emissive colour filters has been recently described by Yamazaki et $a l .{ }^{[124]}$ In this study the authors incorporate a monolayer of dye molecules bound to a titania surface. This construct successfully acts as a sink to quench any photogenerated excitons in the dye molecules, preventing any emission.

The assembly and integration of excitation, detection and optical filtration components within microfluidic devices is a non-trivial process, however in recent years much progress has been made towards fully-integrated, small-footprint diagnostic systems. For example, Hofmann and co-workers reported a stand-alone diagnostic device for assaying urinary human serum albumin (HSA). [119] Here HSA was reacted with Albumin Blue 580, generating a strong emission at $620 \mathrm{~nm}$ when excited with the pLED. Using such an approach, HSA concentrations down to $10 \mathrm{mgL}^{-1}$ were detected within 1 minute. Such sensitivity is more than sufficient for the diagnostic determination of microalbuminuria (increased urinary albumin excretion indicative of renal disease) with clinical cut-off levels between $15-40 \mathrm{mgL}^{-1}$. Additionally, Ryu et al. have described more recently a highly sensitive fluorescence detection system for point-of-care testing in a microfluidic chip, which can be used to detect markers indicative of acute myocardial infarction. ${ }^{[125]}$

\section{Conclusion}

Continuous and segmented flow microfluidic systems have realised much of their early promise in the fields of chemistry and biology. Activities in both areas have focused, and will continue to focus, on high-throughput experimentation on small samples. Moreover, the continuing evolution of genomics, proteomics, drugdiscovery and high-throughput screening requires new tools able to extract and process enormous amounts of information. In this respect, microfluidics has already made important contributions. For example, the ability to perform analyses at the single cell or single molecule level has enabled cohort and generational cell studies to be carried out rapidly and reproducibly. In nanoparticle synthesis, the use of microfluidics offers direct routes to low polydispersity and high quality products and the reality of on-demand synthesis. And in molecular analysis, microfluidics enables enhanced sensitivity and low volume automation of complex analytical techniques.

The future for microfluidic systems is difficult to predict, as with any disruptive technology. However, it seems clear that in any field where low frequency events, or high sensitivity analyses, or indeed highly concentration, temperature or time dependent syntheses need to be performed, microfluidic systems will play an increasingly dominant role.

\section{Acknowledgements}

The authors would like to acknowledge the contributions of all past and present members of the deMello Laboratory at Imperial College London and ETH Zürich, and our many collaborators throughout the world. 


\section{Received: February 6, 2012}

[1] A. Huebner, S. Sharma, M. Srisa-Art, F. Hollfelder, J. B. Edel, A. J. deMello, Lab Chip 2008, 8,1244

[2] a) S. C. Jakeway, A. J. deMello, E. L. Russell, Fresenius' J. Anal. Chem. 2000, 366, 525; b) P.-A. Auroux, Y. Koc, A. deMello, A. Manz, P. J. R. Day, Lab Chip 2004, 4, 534; c) J. Hong, J. B. Edel, A. J. deMello, Drug Discovery Today 2009, 14, 134; d) S. Gulalti, V. Rouilly, X Niu, J. Chappell, R. I. Kitney, J. B. Edel, P. S. Freemont, A. J. deMello, J. R. Soc., Interface 2009, 6, S493; e) S. Cho, D.-K. Kang, J. Choo, A. J. deMello, S.-I. Chang, BMB Rep. 2011, 44 , 705 .

[3] a) M. C. Mitchell, V. Spikmans, A. J. deMello, Analyst 2001, 126, 24; b) A. J. deMello, R. Wootton, Lab Chip 2002, 2, 7N; c) R. C. R. Wootton, R. Fortt, A. J. deMello, Org. Process Res. Dev. 2002, 6, 187; d) R. C. R. Wootton, R. Fortt, A. J. deMello, Lab Chip 2002, 2, 5 e) R. Fortt, R. C. R. Wootton, A. J. deMello, Org. Process Res. Dev. 2003, 7, 762; f) R. C. R. Wootton, A. J. deMello, Chem. Commun. 2004, 266; g) P. W. Miller, N. J. Long, A. J. deMello, R. Vilar, J. Passchier, A. Gee, Chem. Commun. 2005, 1; h) A. Iles, R. Fortt, A. J. deMello, Lab Chip 2005, 5, 540; i) A. J. deMello, Nature 2006, 442, 394; j) P. W. Miller, L. E. Jennings, A. J. deMello, A. D. Gee, N. J. Long, R. Vilar, Adv. Synth. Catal. 2009, 351, 3260; k) C. J. Cullen, R. C. R. Wootton, A. J. deMello, $J$. Appl. Phys. 2009, 105, 102007.

[4] a) M. C. Mitchell, V. Spikmans, A. Manz, A. J deMello, J. Chem. Soc., Perkin Trans. 12001 , 514; b) P. W. Miller, N. J. Long, A. J. deMello, R. Vilar, H. Audrain, D. Bender, J. Passchier, A. Gee, Angew. Chem. 2007, 119, 2933; c) P. W. Miller, A. J. deMello, A. D. Gee, Curr Radiopharm. 2010, 3, 254; d) P. W. Miller, H. Audrain, D. Bender, A. J. deMello, A. D. Gee, N. J. Long, R. Vilar, Chem. Eur. J. 2011, 17 460.

[5] A. deMello, H. Morgan, Lab Chip 2011, 11,1191.

[6] a) A. J. deMello, R. C. R. Wootton, Nat. Chem. 2001, 1, 28; b) A. J. deMello, Anal. Bioanal. Chem. 2002, 372, 12; c) A. J. deMello, A. T. Woolley, Curr. Opin. Chem. Biol. 2010, 14, 545

[7] A. J. deMello, M. Habgood, N. L. Lancaster, T. Welton, R. C. R. Wootton, Lab Chip 2004, 4, 417.

[8] F. G. Bessoth, A. J. deMello, A. Manz, Anal Commun. 1999, 36, 213.

[9] M. Srisa-Art, A. J. deMello, J. B. Edel, Phys Rev. Lett. 2008, 101, 014502 .

[10] A. deMello, Lab Chip 2002, 2, 31N.

[11] a) R. C. R. Wootton, A. J. deMello, Lab Chip 2006, 6, 471; b) Y. Koc, A. J. deMello, G. McHale, M. I. Newton, P. Roacha, N. J. Shirtcliffe, Lab Chip 2008, 8, 582.

[12] X. Casadevall i Solvas, A. deMello, Chem. Commun. 2011, 47, 1936.

[13] J. D. Tice, H. Song, A. D. Lyon, R. F. Ismagilov, Langmuir 2003, 19, 9127.

[14] M. R. Bringer, C. J. Gerdts, H. Song, J. D. Tice, R. F. Ismagilov, Philos. Trans. R. Soc., A 2004 , $362,1087$.

[15] M. Srisa-Art, I. C. Bonzani, A. Williams, M. M. Stevens, A. J. deMello, J. B. Edel, Analyst 2009, 134, 2239

[16] M. Srisa-Art, D.-K. Kang, J. Hong, H. Park, R J. Leatherbarrow, J. B. Edel, S.-I. Chang, A. J. deMello, ChemBioChem 2009, 10, 1605 .

[17] P. B. Umbanhowar, V. Prasad, D. A. Weitz, Langmuir 2000, 16, 347

[18] H. Song, J. D. Tice, R. E. Ismagilov, Angew. Chem. 2003, 115, 791.

[19] S. L. Anna, N. Bontoux, H. A. Stone, Appl. Phys. Lett. 2003, 82, 364.
[20] R. O. Grigoriev, M. F. Schatza, V. Sharma, Lab Chip 2006, 6, 1369.

[21] C. Holtze, A. C. Rowat, J. J. Agresti, J. B. Hutchison, F. E. Angilè, C. H. J. Schmitz, S. Köster, H. Duan, K. J. Humphry, R. A. Scanga, J. S. Johnson, D. Pisignano, D. A. Weitz, Lab Chip 2008, 8, 1632 .

[22] A. B. Theberge, G. Whyte, M. Frenzel, L. M. Fidalgo, R. C. R. Wootton, W. T. S. Huck, Chem. Commun. 2009, 6225.

[23] X. Niu, S. Gulati, J. B. Edel, A. J. deMello, Lab Chip 2008, 8, 1837 .

[24] D. R. Link, S. L. Anna, D. A. Weitz, H. A. Stone, Phys. Rev. Lett. 2004, 92, 054503.

[25] J. Hong, M. Choi, J. B. Edel, A. J. deMello, Lab Chip 2010, 10, 2702.

[26] X. Niu, M. Zhang, S. Peng, W. Wen, P. Sheng, Biomicrofluidics 2007, 1, 044101.

[27] T. Henkel, T. Bermig, M. Kielpinski, A Grodrian, J. Metze, J. M. Köhler, Chem. Eng. J. 2004, 101, 439 .

[28] A. Huebner, D. Bratton, G. Whyte, M. Yang, A. J. deMello, C. Abell, F. Hollfelder, Lab Chip 2009, 9, 692

[29] M. Zagnoni, C. N. Baroud, J. M. Cooper, Phys. Rev. E 2009, 80, 046303.

[30] J. Hong, M. Choi, A. J. deMello, J. B. Edel, BioChip J. 2009, 3, 203

[31] X. Niu, F. Gielen, A. J. deMello, J. B. Edel, Anal. Chem. 2009, 81, 7321.

[32] X. Niu, F. Gielen, J. B. Edel, A. J. deMello, Nat. Chem. 2011, 3, 437

[33] C. H. J. Schmitz, A. C. Rowat, S. Köster, D. A. Weitz, Lab Chip 2009, 9, 44.

[34] C. Holtze, A. C. Rowat, J. J. Agresti, J. B. Hutchinson, F. E. Angilè, C. H. J. Schmitz, S. Köster, H. Duan, K. J. Humphry, R. A. Scanga, J. S. Johnson, D. Pisignano, D. A. Weitz, Lab Chip 2008, 8, 1632

[35] Y. Schaerli, F. Hollfelder, Mol. BioSyst. 2009, $5,1392$.

[36] B. Alberts, A. Johnson, J. Lewis, M. Raff, K. Roberts, P. Walter, in 'Molecular Biology of the Cell', Garland Science, New York, 2002.

[37] R. Phillips, T. Ursell, P. Wiggins, P. Sens, Nature 2009, 459, 379.

[38] M. Abkarian, E. Loiseau, G. Massiera, Soft Matter 2011, 7, 4610

[39] a) A. Jahn, S. M. Stavis, J. S. Hong, W. N. Vreeland, D. L. DeVoe, M. Gaitan, ACS Nano 2010, 4, 2077; b) J. Thiele, D. Steinhauser, T. Pfohl, S. Förster, Langmuir 2010, 26, 6860.

[40] A. Frost, Curr. Biol. 2011, 21, R811.

[41] a) H. Sakai, K. Sou, H. Horinouchi, K. Kobayashi, E. Tsuchida, J. Intern. Med. 2007, 263,4 ; b) P. Stano, P. Carrara, Y. Kuruma, T. P. de Souza, P. L. Luisi, J. Mater. Chem. 2011, 21 , 18887.

[42] J. P. Reeves, R. M. Dowben, J. Cell. Physiol. 1969, 73,49 .

[43] A. Moscho, O. Orwar, D. T. Chiu, B. P. Modi, R. N. Zare, Proc. Natl. Acad. Sci. USA 1996, 93, 11443.

[44] M. I. Angelova, D. S. Dimitrov, Faraday Discuss. Chem. Soc. 1986, 81, 303.

[45] a) D. J. Estes, M. Mayer, Biochim. Biophys. Acto 2005, 1712, 152; b) D. J. Estes, S. R. Lopez, A. O. Fuller, M. Mayer, Biophys. J. 2006, 91, 233.

[46] J. C. Stachowiak, D. L. Richmond, T. H. Li, F. Brochard-Wyarte, D. A. Fletcher, Lab Chip 2009, 9, 2003.

[47] S. Ota, S. Yoshizawa, S. Takeuchi, Angew. Chem. 2009, 48, 6533.

[48] a) Y.-C. Tan, K. Hettiarachchi, M. Siu, Y.-R. Pan, A. P. Lee, J. Am. Chem Soc, 2006, 128 , 5656; b) S. Sugiura, T. Kuroiwa, T. Kagota, M. Nakajima, S. Sato, S. Mukataka, P. Walde, S. Ichikawa, Langmuir 2008, 24, 4581; c) H. C. Shum, D. Lee, I. Yoon, T. Kodger, D. A. Weitz, Langmuir 2008, 24, 7651; d) S. Matosevic, B. M. Paegel, J. Am. Chem. Soc. 2011, 133, 2798.
[49] W. Hanke, W.-R. Schlue, in 'Planar Lipid Bilayers: Methods and Applications', Academic Press Ltd., London, 1993.

[50] M. Montal, P. Mueller, Proc. Natl. Acad. Sci. USA 1972, 69, 3561

[51] H. Bayley, B. Cronin, A. Heron, M. A. Holden, W. L. Hwang, R. Syeda, J. Thompson, M. Wallace, Mol. BioSyst. 2008, 4, 1191.

[52] a) K. Funakoshi, H. Suzuki, S. Takeuchi, Anal. Chem. 2006, 78, 8169; b) M. A. Holden, D. Needham, H. Bayley, J. Am. Chem. Soc. 2007, 129,8650 .

[53] C. E. Stanley, K. S. Elvira, X. Z. Niu, A. D. Gee, O. Ces, J. B. Edel, A. J. deMello, Chem Commun. 2010, 46, 1620.

[54] P. M. P. Lanigan, T. Ninkovic, K. Chan, A. J. deMello, K. R. Willison, D. R. Klug, R. H Templer, M. A. A. Neil, O. Ces, Lab Chip 2009, 9, 1096

[55] A. Salehi-Reyhani, J. Kaplinsky, E. Burgin, M. Novakova, A. J. deMello, R. H. Templer, P. Parker, M. A. A. Neil, O. Ces, P. French, K. R. Willison, D. Klug, Lab Chip 2010, 11, 1256

[56] H. Bow, I. V. Pivkin, M. Diez-Silva, S. J. Goldfless, M. Dao, J. C. Niles, S. Suresh, J. Han, Lab Chip 2011, 11, 1065.

[57] J. B. Edel, A J. deMello, Appl. Phys. Lett. 2007, 90, 053904.

[58] M. E. Vincent, W. Liu, E. B. Haney, R. F. Ismagilov, Chem. Soc. Rev. 2010, 39, 974

[59] A. Huebner, M. Srisa-Art, D. Holt, C. Abell, F Hollfelder, A. J. deMelloc, J. B. Edel, Chem Commun. 2007, 1218.

[60] J. Hong, A. J. deMello, S. N. Jayasinghe, Biomed. Mater. 2010, 5, 021001.

[61] A. Huebner, L. F. Olguin, D. Bratton, G. Whyte, W. T. S. Huck, A. J. deMello, J. B. Edel, C. Abell, F. Hollfelder, Anal. Chem. 2008, 80, 3890.

[62] J. J. Agresti, E. Antipov, A. R. Abate, K. Ahn, A. C. Rowat, J.-C. Baret, M. Marquez, A. M Klibanov, A. D. Griffiths, D. A. Weitz, Proc. Natl. Acad. Sci. USA 2010, 107, 4004.

[63] J. F. Edd, D. Di Carlo, K. J. Humphry, S. Köster, D. Irimia, D. A. Weitz, M. Toner, Lab Chip 2008, 8,1262 .

[64] A. J. deMello, Lab Chip 2002, 2, 48N.

[65] a) N. Burggraf, B. Krattiger, A. J. deMello, N. F. de Rooij, A. Manz, Analyst 1998, 123, 1443; b) S. Sirichai, A. J. deMello, Analyst 2000, 125 , 133; c) S. Sirichai, A. J. deMello, Electrophoresis 2001, 22, 348; d) S.-A. Leung, A. J. deMello, J. Sep. Sci. 2002, 25, 1346; e) N. P. Beard, A. J. deMello, Electrophoresis 2002, 23, 1722; f) N. P. Beard, C.-X. Zhang, A. J. deMello, Electrophoresis 2003, 24, 732; g) N. P. Beard, J. B. Edel, A. J. deMello, Electrophoresis 2004 25,$2363 ;$ h) F. Pereira, S. Hassard, J. Hassard, A. deMello, Electrophoresis 2009, 30, 2100.

[66] X. Z. Niu, B. Zhang, R. T. Marszalek, O. Ces, J. B. Edel, D. R. Klug, A. J. deMello, Chem. Commun. 2009, 6159.

[67] K. Vijayakumar, S. Gulati, A. J. deMello, J. B Edel, Chem. Sci. 2010, 1, 447

[68] M. F. Yanik, C. B. Rohde, C. Pardo-Martin, Annu. Rev. Biomed. Eng. 2011, 13, 185

[69] a) C. J. Kenyon, Nature 2010, 464, 504; b) S. E. Hulme, G. Whitesides, Angew. Chem. Int. Ed. 2011, 50, 4774.

[70] W. Shi, H. Wen, B. Lin, J. Qin, Top. Curr. Chem 2011, 304, 323.

[71] X. Casadevall i Solvas, F. M. Geier, A. M. Leroi, J. G. Bundy, J. B. Edel, A. J. deMello, Chem. Commun. 2011, 47, 9801

[72] J. Clausell-Tormos, D. Lieber, J.-C. Baret, A. El-Harrak, O. J. Miller, L. Frenz, J. Blouwolff, K. J. Humphry, S. Köster, H. Duan, C. Holtze, D. A. Weitz, A. D. Griffiths, C. A. Merten, Chem. Biol. 2008, 15, 427.

[73] W. Shi, H. Wen, Y. Lu, Y. Shi, B. Lin, J. Qin Lab Chip 2010, 10, 2855. 
[74] a) M. Green, Angew. Chem., Int. Ed. 2004, 43, 4129; b) M. N. Rhyner, A. M. Smith, W. Gao, H. Mao, L. Yang, S. Nie, Nanomedicine 2006 , 1, 209.

[75] S. Kim, Y. T. Lim, E. G. Soltesz, A. M. De Grand, J. Lee, A. Nakayama, J. A. Parker, T Mihaljevic, R. G. Laurence, D. M. Dor, L. H. Cohn, M. G. Bawendi, J. V. Frangioni, Nat. Biotechnol. 2004, 22, 93.

[76] S. Marre, K. F. Jensen, Chem. Soc. Rev. 2010 39, 1183.

[77] a) J. B. Edel, R. Fortt, J. C. deMello, A. J deMello, Chem. Commun. 2002, 1136; b) J. deMello, A. deMello, Lab Chip 2004, 4, 11N.

[78] a) J. B. Edel, S. Krishnadasan, J. Torvilla caoRomero, R. Vilar-Compte, J. C. deMello, A. J. deMello, Transducers '03, Int. Conf. SolidState Sens., Actuators Microsyst., Dig. Tech. Pap., 12th 2003, 1730; b) D. Shalom, R. C. R. Wootton, R. F. Winkle, B. F. Cottam, R. Vilar, A. J. deMello, P. C. Wilde, Mater. Lett. 2007, 61, 1146

[79] S. Krishnadasan, J. Tovilla, R. Vilar, A. J. deMello, J. C. deMello, J. Mater. Chem. 2004 $14,2655$.

[80] S. Krishnadasan, R. J. C. Brown, A. J. deMello, J. C. deMello, Lab Chip 2007, 7, 1377.

[81] C.-X. Zhao, L. He, S. Z. Qiao, A. P. J. Middelberg, Chem. Eng. Sci. 2011, 66, 1463.

[82] S. Krishnadasan, A. Yashina, A. J. deMello, J. C. deMello, in 'Advances in Chemical Engineering', volume 38, Ch. 4, Ed. J. C. Schouten, Academic Press, 2010, p. 195.

[83] I. Shestopalov, J. D. Tice, R. F. Ismagilov, $L a b$ Chip 2004, 4, 316.

[84] K. Kumar, A. M. Nightingale, S. H Krishnadasan, N. Kamaly, M. WylenzinskaArridge, K. Zeissler, W. R. Branford, E. Ware, A. J. deMello, J. C. deMello, J. Mater. Chem. 2012, DOI: $10.1039 / \mathrm{C} 2 \mathrm{JM} 30257 \mathrm{H}$

[85] A. J deMello, C. J. Cullen, R. Fortt, R. C. R. Wootton, in 'Handbook of Capillary and Microchip Electrophoresis and Associated Microtechniques', Ch. 14, Ed. J. P. Landers, CRC Press, 2008, p. 1185.

[86] S. Marre, J. Baek, J. Park, M. G. Bawendi, K. F. Jensen, JALA 2009, 14, 367.

[87] T. J. White, N. Arnheim, H. A. Erlich, Trends Genet. 1989, 5, 185.

[88] M. U. Kopp, A. J. deMello, A. Manz, Science 1998, 280, 1046.

[89] A. T. Woolley, D. Hadley, P. Landre, A. J. deMello, R. A. Mathies, M. A. Northrup, Anal. Chem. 1996, 68, 4081 .

[90] B. Vogelstein, K. W. Kinzler, Proc. Natl. Acad. Sci. USA 1999, 96, 9236.

[91] Y. Schaerli, R. C. Wootton, T. Robinson, V. Stein, C. Dunsby, M. A. A. Neil, P. M. W.
French, A. J. deMello, C. Abell, F. Hollfelder, Anal. Chem. 2009, 81, 302.

[92] C. Zhang, D. Xing, Chem. Rev. 2010, 110, 4910.

[93] M. A. Schwarz, P. C. Hauser, Lab Chip 2001, 1, 1

[94] A. J. deMello, Lab Chip 2003, 3, 29N.

[95] a) E. K. Hill, A. J. deMello, Analyst 2000 , 125, 1033; b) X. Casadevall i Solvas, X. Niu, K. Leeper, S. Cho, S.-I Chang, J. B. Edel, A. J. deMello, J. Vis. Exp. 2011, 58, e3437.

[96] S. Weiss, Nat. Struct. Biol. 2000, 7, 724.

[97] a) J. B. Edel, E. K. Hill, A. J. deMello, Analyst 2001, 126, 1953; b) J. B. Edel, A. J. deMello, Phys. Chem. Chem. Phys. 2003, 5, 3973; c) J. B. Edel, A. J. deMello, Anal. Sci. 2003, 19, 1065.

[98] M. Srisa-Art, A. J. deMello, J. B. Edel, J. Phys. Chem. B 2010, 114, 15766.

[99] J. B. Edel, P. Lahoud, A. E. G. Cass, A. J. deMello, J. Phys. Chem. B 2007, 111, 1129.

[100] A. J. deMello, J. B. Edel, J. Appl. Phys. 2007, 101, 084903.

[101] M. Srisa-Art, A. J. deMello, J. B. Edel, Chem. Commun. 2009, 6548.

[102] M. Srisa-Art, A. J. deMello, J. B. Edel, Anal. Chem. 2007, 79, 6682

[103] S. Sakakihara, S. Araki, R. Iino, H. Noji, Lab Chip 2010, 10, 3355.

[104] R. K. P. Benninger, O. Hofmann, B. Önfelt, I. Munro, C. Dunsby, D. M. Davis, M. A. A. Neil, P. M. W. French, A. J. deMello, Angew. Chem. 2007, 119, 2278.

[105] a) R. K. P. Benninger, Y. Koc, O. Hofmann, J. Requejo-Isidro, M. A. A. Neil, P. M. W. French, A. J. deMello, Anal. Chem. 2006, 78, 2272; b) T. Robinson, Y. Schaerli, R. Wootton, F. Hollfelder, C. Dunsby, G. Baldwin, M. Neil, P. French, A. deMello, Lab Chip 2009, 9, 3437.

[106] X. Casadevall i Solvas, M. Srisa-Art, A. J. deMello, J. B. Edel, Anal. Chem. 2010, 82, 3950.

[107] T. Robinson, P. Valluri, H. B. Manning, D. M. Owen, I. Munro, C. B. Talbot, C. Dunsby, J. F. Eccleston, G. S. Baldwin, M. A. A. Neil, A. J. deMello, P. M. W. French, Opt. Lett. 2008, 33, 1887.

[108] R. K. P. Benninger, O. Hofmann, J. McGinty, J. Requejo-Isidro, I. Munro, M. A. A. Neil, A. J. deMello, P. M. W. French, Opt. Express 2005. 13,6275 .

[109] a) S. C. Jakeway, A. J. deMello, Anal. Chem. 2001, 126, 1505; b) S. C. Jakeway, A. J. deMello, Micro Total Anal. Syst. 2001, Proc. UTAS 2001 Symp., 5th 2001, 347; c) S.-A. Leung, J. B. Edel, R. C. R. Wootton, A. J. deMello, Meas. Sci. Technol. 2004, 15, 290

[110] S.-A. Leung, R. F. Winkle, R. C. R. Wootton, A. J. deMello, Analyst 2005, 130, 46.
[111] a) G. Wang, C. Lim, L. Chen, H. Chon, J. Choo, J. Hong, A. J. deMello, Anal. Bioanal. Chem. 2009, 394, 1827; b) C. Lim, J. Hong, B. Geun Chung, A. J. deMello, J. Choo, Analyst 2010, 135,837 .

[112] K. L. A. Chan, X. Niu, A. J. deMello, S. G. Kazarian, Lab Chip 2010, 10, 2170.

[113] K. L. A. Chan, S. Gulati, J. B. Edel, A. J. deMello, S. G. Kazarian, Lab Chip 2009, 9, 2909.

[114] A. J. deMello, Lab Chip 2001, 1, 7N.

[115] K. L. A. Chan, X. Niu, A. J. deMello, S. G. Kazarian, Anal. Chem. 2011, 83, 3606.

[116] M. P. Cecchini, J. Hong, C. Lim, J. Choo, T. Albrecht, A. J. deMello, J. B. Edel, Anal. Chem. 2011, 83, 3076.

[117] P. Yager, T. Edwards, E. Fu, K. Helton, K. Nelson, M. R. Tam, B. H. Weigl, Nature 2006, 442, 412.

[118] O. Hofmann, D. D. C. Bradley, J. C. deMello, A. J. deMello, in 'Organic Semiconductors in Sensor Applications', Ch. 4, Ed. D. A. Bernards, R. M Owens, G. G. Malliaras, Springer, 2008, p. 97.

[119] O. Hofmann, X. Wang, J. C. deMello, D. D. C. Bradley, A. J. deMello, Lab Chip 2005, 5, 863.

[120] J. B. Edel, N. P. Beard, O. Hofmann, J. C. deMello, D. D. C. Bradley, A. J. deMello, Lab Chip 2004, 4, 136.

[121] a) O. Hofmann, A. deMello, GIT Lab. J. 2004, 5, 2; b) X. Wang, O. Hofmann, J. Huang, E. M. Barrett, R. Das, A. J. deMello, J. C. deMello, D. D. C. Bradley, Proc. SPIE 2006, 6036, 603610.

[122] a) O. Hofmann, P. Miller, P. Sullivan, T. S. Jones, J. C. deMello, D. D.C. Bradley, A. J. deMello, Sens. Actuators, B 2005, 106, 878; b) X. Wang, O. Hofmann, R. Das, E. M. Barrett, A. J. deMello, J. C. deMello, D. D. C. Bradley, Lab Chip 2007, 7, 58; c) M. Amatatongchai, O. Hofmann, D. Nacapricha, O. Chailapakul, A. J. deMello, Anal. Bioanal. Chem. 2007, 387, 277; d) X. Wang, M. Amatatongchai, D. Nacapricha, O. Hofmann, J. C. deMello, D. D. C. Bradley, A. J. deMello, Sens. Actuators, B 2009, 140, 643.

[123] O. Hofmann, X. Wang, A. Cornwell, S. Beecher, A. Raja, D. D. C. Bradley, A. J. deMello, J. C. deMello, Lab Chip 2006, 6, 981.

[124] M. Yamazaki, O. Hofmann, G. Ryu, L. Xiaoe, T. Kyu Lee, A. J. deMello, J. C. deMello, Lab Chip 2011, 11, 1228 .

[125] G. Ryu, J. Huang, O. Hofmann, C. A. Walshe, J. Y. Y. Sze, G. D. McClean, A. Mosley, S. J. Rattle, J. C. deMello, A. J. deMello, D. D. C. Bradley, Lab Chip 2011, 11, 1664. 